Magna Scientia Advanced Research and Reviews

eISSN: 2582-9394

Cross Ref DOI: $10.30574 / m s a r r$

Journal homepage: https://magnascientiapub.com/journals/msarr/

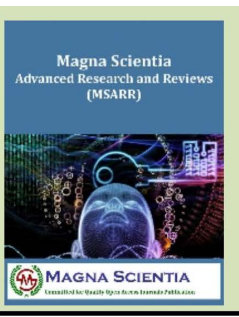

(REVIEW ARTICLE)

\title{
Natural disinfectants: A Review
}

\author{
Basam Basim Mohammed *, Duaa Suhail Shawket, Zainab Owaid Shatti and Enaam Hameed Batah \\ Department of Biology, College of Science, Mustansiriyah University, Baghdad, Iraq.
}

Magna Scientia Advanced Research and Reviews, 2022, 04(01), 020-026

Publication history: Received on 29 December 2021; revised on 17 January 2022; accepted on 19 January 2022

Article DOI: https://doi.org/10.30574/msarr.2022.4.1.0081

\begin{abstract}
Disinfection is defined as the destruction of microorganisms, not necessarily destroy all the microbes but may reducing them to an acceptable level. Thus, it could stop the chain of bugs transmission to avoid infections. Antimicrobials are divided into antimicrobial agents and antibiotics. Disinfectants or hand sanitizers are used to prevent microbial contamination on inanimate objects that are present in the environment; consequently, avoiding of disease occurrence. While antibiotics are used for therapeutic purposes. Microbial growth is controlled by using natural, chemical and physical agents. Most investigations that are conducted in vitro showed that natural agents could inhibit or kill the growth of pathogens and its efficiency depends on their bio components. This article will focus on natural antimicrobial agents as alternatives to chemical disinfectants. Natural resources include: plants and microbes.
\end{abstract}

Keywords: Antimicrobial agents; Natural products; Disinfection; Surfaces; Microorganisms; Hand sanitizers

\section{Introduction}

Microorganisms could be transmitted from animated and inanimate sources to human. Both sources might be contaminated resulted in causing disease. The exposure rate of microbes in healthcare facilities, microbial laboratories of universities, and public toilets is higher than other places [1]. Pathogens including bacteria, fungi, viruses, and protozoa are able to survive on inanimate surfaces for months, then could be transferred to the hand unless these surfaces are cleansed by disinfectants [2]. However, if these surfaces remain contaminated, bugs can be picked up by hands. Furthermore, contaminated hands can transfer pathogens to other communal objects [3]. Thus, disinfection using hand sanitizers is necessary in the everyday life to prevent the transmission of infectious diseases [4].

Some microorganisms can cause infections, while others are considered as antimicrobials. According to a review published by Imogen and Lovleen [5] antimicrobial agent is a substance or mixture of substances, from natural, semisynthetic or synthetic origin which removes or destroys all kinds of microorganisms, but not necessarily their spores on inanimate surfaces. It is important to know that all antibiotics used are antimicrobials but not all antimicrobial agents are antibiotics. Most disinfectants that are used for cleaning surfaces in hospitals, health centers, laboratories, and household settings are chemicals used to kill all types of microorganisms and to prevent infection [6].

\subsection{According to their efficacy, there are three levels of disinfectants}

- High-level disinfectants: which eliminates most forms of bacteria even spores, many viruses and fungi.

- Intermediate-level disinfectants: which destroy all forms of the microbes except spores of bacteria.

- Low-level disinfectants: which can only kill vegetative bacteria and some fungi and viruses.

-

\footnotetext{
${ }^{*}$ Corresponding author: Basam Basim Mohammed

Department of Biology, College of Science, Mustansiriyah University, Baghdad, Iraq.

Copyright $(2022$ Author(s) retain the copyright of this article. This article is published under the terms of the Creative Commons Attribution Liscense 4.0.
} 


\subsection{Factors affecting the effectiveness of a disinfectant are}

- Number and kind of microbes.

- $\quad$ Potency and concentration of disinfectants.

- $\quad$ Physical and chemical factors (temperature, water, oxygen, pressure ,UV radiation....etc)

- The contact time of disinfectants with surfaces.

Living organisms produce natural antimicrobial agents that have high effectiveness; previous studies indicated that plants and their oils have been given more attention in developed countries due to their active compounds. Some parts of plant like: roots, seeds, stems, flowers, and leaves have antibacterial and antifungal substances that can either inhibit the growth of pathogens or kill them [7]. Moreover, there are several factors affecting the action of natural antimicrobials including, acidity, osmotic effect, production of $\mathrm{H}_{2} \mathrm{O}_{2}$ and concentration of active components [8].

Microorganisms are another source of natural antimicrobials such as Lactobacillus strains, Acetobacter aceti, Saccharomyces cerevisiae. These kinds of microorganisms produce high content of bioactive substances which have strong inhibitory effect against other microorganisms [9]. This review summarizes the use of common natural antimicrobials as alternative disinfectants against microbes.

\section{Common natural antimicrobial agents}

\subsection{Citrus fruits}

Citrus fruits are a juicy fruit with a sharp taste, grown in warm regions, and have leathery aromatic rinds [10].

\subsubsection{Common types of fruits}

such as lime, lemons, bitter oranges and grape fruits.

\subsubsection{Used parts}

juice, peel and essential oils.

\subsubsection{The major antimicrobial compounds of juice and peels are:}

- $\quad$ Ascorbic acid and citric acid have a pH ranging from 3 - 6.

- $\quad$ Flavonoids such as naringin, hesperidin, quercetin, rutin, naringenin.

- Phenolic compounds (PCs) such as caffeic acid, cinnamic acid, pyrogallol, eugenol, gallic acid and coumarins,.

- Saponin compounds.

- $\quad$ Polyphenols [11]

\subsection{Essential oils contain of}

Carvone, limonene, phenolic compounds, tannins monoterpenes, sesquiterpenese, alcohols, aldehydes, ketones and esters, protopine and corydaline alkaloids, lactons, polyacetylene, hypericin and pseudohypericin compounds [12].

\section{Bioethanol}

Bioethanol is a natural form of alcohol produced from agricultural products through microbial fermentation. Raw materials of carbohydrate sources or biomass containing cellulose were used to obtain bioethanol. The production of bioethanol includes hydrolysis of complex carbohydrates or cellulose in the presence of degradation enzymes to obtain fermentable simple sugars followed by fermentation to convert sugars into ethanol, then distillation to purify the ethanol [13][14].

\subsection{Plants containing sugar or starch include:}

- Sugarcane.

- Corn.

- $\quad$ Rice.

- Wheat.

- Date waste. 
- Legumes.

\section{Natural Vinegar}

Natural Vinegar is an acidic liquid produced from organic sources through two-step process including, fermentation of simple sugars to ethanol by using saccharomyces cerevisiae under anaerobically conditions, conversion of ethanol to acetic acid through aerobic fermentation by acetic acid bacteria [15].

\subsection{Common types of vinegar}

- Apple cider vinegar.

- Grape vinegar.

- $\quad$ Dates vinegar.

\subsection{Natural vinegar consists of}

- Organic acids: such as acetic acid which has low $\mathrm{pH}$ values.

- $\quad$ polyphenolic/phenolic compounds: such as catechin, epicatechin, chlorogenic acid, gallic acid, caffeic acid, pcoumaric acid and the grape vinegar contains ferulic acid, and syringic acid.

- $\quad$ Flavonoids [16].

\subsubsection{Salt}

Salt is one of the products commonly used in the world found naturally in seawater and in certain rocks. Chemically, it contains two elements: sodium ( $\mathrm{Na}$ ) and chloride $(\mathrm{Cl})$ as crystalline compound. Before 5000 years ago, the Chinese observed that types of meat soaked in saline solutions prolonged the preservation time of food [17].

Common types of salts

- $\quad$ Table salt.

- Himalayan pink salt.

- Sea salt.

\subsubsection{Tea}

Tea is one of the most commonly consumed drinks. It is obtained from leaves of the Camellia sinensis. Determination of the resulted tea type depends on the processing of tea leaves treated with oxygen. Green and white teas are not oxidized (unfermented), while black teas are fully oxidized (fermented) leading to a darker colored liquid [18].

\subsubsection{The three major types of tea}

- $\quad$ Black tea.

- Green tea.

- White tea.

\subsubsection{Main bioactive compounds in tea}

- Polyphenols: phenolic acids, catechins.

- $\quad$ Flavonoids.

- Tannins [19].

\subsection{Aromatic Plants}

Aromatic plant is any plant that has volatile compounds in one or more of its parts such as: roots, stems, leaves, etc. These plants contain many bioactive substances that serve as defense mechanisms against pests such as microorganisms and insects. Therefore, a number of plants have been applied in traditional medicine for many years. Additionally, dried or liquid extracts and essential oils are derived from these plants [20].

\subsection{Essential oils}

Essential oils are natural metabolic secretions isolated from flowers and leaves of plants. 


\subsection{Plant Extracts}

Plant Extracts is the separation process of certain components present in the plant (solid parts) by using selective solvents like ethanol, methanol and water through standard procedures and the obtained solution is the desired extract.

\subsection{The most common aromatic plants are}

- Clove

- Sage

- Basil.

- Peppermint

- Thyme

- Tea tree oil

\subsection{Bioactive components in the aromatic plants:}

- Polyphenols /Phenolic compounds.

- Quinines.

- Flavonols/Flavonoids.

- Alkaloids.

- Terpenoids.

- $\quad$ Eugenol [21].

\section{Cell-free supernatant (CFS) of Lactic acid bacteria (LAB)}

It is a fluid of bioactive substances that have inhibitory activity secreted into the supernatant obtained by centrifugation (6,000 rpm/15 minutes) of broth containing lactic acid bacteria cultures, this supernatant will be filtered through Millipore $0.22-0.45 \mathrm{~mm}$ to remove cells [22].

\subsection{CFS derived from main LAB genera}

- Lactobacillus

- Leuconostoc

- Pediococcus

- $\quad$ Streptococcus

- Lactococcus

- $\quad$ Enterococcus [23]

\subsection{Main antimicrobial compounds in CFS}

- Bacteriocins.

- Defensins.

- Lactoperoxidase.

- Organic acids .

- $\quad$ Hydrogen peroxide[24].

\section{Mechanism of action of natural antimicrobial components}

Important components in plants which have antimicrobial effect are: phenolics (simple and polyphenols), phenolic acids, tannins, flavones, flavonoids, flavonols, quinones, terpenenes or terpenoids, alkaloids and organic acids e.g., sorbic, propionic, citric acid. These bioactive compounds have the ability to damage microbial cells causing deformation in structure and functionality of the bacterial cell. Several modes of action have been reported which may involve: suppression of cell wall synthesis, cell metabolism, protein synthesis, nucleic acid synthesis, disruption of bacterial cytoplasmic membrane and alteration of cell membrane function. While the essential oil of plants acts principally on the solubility of lipid bilayer of bacterial cell membrane [25]. 
Many microorganisms could be inhibited or killed by salt in a process known as osmosis. If there is a higher concentration of dissolved salt outside of the microbial cell (a hypertonic environment), then water will diffuse out of the cell causing disfunction of bacterial proteins and shrinkage of the cell. This phenomenon is called plasmolysis and this is the reason of food preservation in high concentrations of salt [17].

Organic acids such as ascorbic acid, citric acid, acetic acid and lactic acid, have inhibitory effects on microbes since their spread through the bacterial cell membrane leads to separation of protons from anions, eventually inhibiting the balance of electrons within cells. Moreover, low $\mathrm{pH}$ value has a significant antimicrobial effect resulting in growth inhibition of microbes that are less tolerant to acidity[11][24].

Bioethanol can rupture the microbial cell wall and microbial membrane when alcohol molecules break down the proteins present in the bacterial structure resulting in protein denaturation, loss of protective cell barrier, dehydration and quick death [13].

Catechins in all types of tea have antimicrobial properties. Direct inhibitory effects of tea catechins cause degradation of fatty acid synthesis in the lipid bilayer membrane and inhibition of enzymes activity causing loss of cell structure and function then cell death [19].

Lactic acid bacteria (LAB) are capable to produce antimicrobial substances including: organic acids: (formic, acetic, propionic, butyric, succinic and lactic acids) these acids are responsible of decreasing the pH levels which is not appropriate for the growth of several microbes. Hydrogen peroxide is another compound produced by LAB; it has a strong oxidizing effect on microbial cells. While other types of LAB produce toxins (bacteriocins), these toxins have antibacterial activity against various pathogens [26].

\section{Conclusion}

Surface disinfectants and hand sanitizers derived from natural agents have antimicrobial properties and do not have any undesirable effects. In addition to that, these natural antimicrobial agents are inexpensive, easy to use, obtainable and safe. Thus, natural antimicrobials can be applied to inanimate surfaces and skin of human or even in oral cavity as mouthwash.

Chemical substances that are used to clean hand or surfaces have many side effects like itching, irritation causing skin disorders like dermatitis and eczema. Therefore, it is preferred to introduce various forms of natural antimicrobial agents such as soaps, spray, foams, wet wipes, gel, mouth rinse or wash solutions. Other antimicrobial products of daily usages can also be synthesized, like cleansers of makeup tools, food wash solutions and solutions used for cleansing hard surfaces of personal items such as mobile phones.

This review recommends the application of more than one natural ingredient to achieve a synergistic effect with more rapid action and effectiveness against a broad spectrum of microbes that cause spoilage and infections. The combination of two constituents will have a stronger inhibitory effect compared to the effect of a single ingredient.

\section{Compliance with ethical standards}

\section{Acknowledgments}

The author would like to thank Mustansiriyah University (www.uomustansiriyah.edu.iq); College of Science, Baghdad Iraq ; for its support of this review.

\section{Disclosure of conflict of interest}

No conflict of interest to be declared.

\section{References}

[1] Mohammed BB. Identification of Bacterial Isolates from Hand Dryers of Malls Toilets in the City of Baghdad and Detection of their Virulence Factors. Annals of the Romanian Society for Cell Biology. 2021; 25(6): 3847 - 3858. 
[2] Jia Jing JL, Yi TP, Rajendran JC, Bose JR. Tharmalingam MN and Madheswaran T . Hand Sanitizers: A Review on Formulation Aspects, Adverse Effects, and Regulations. International Journal of Environmental Research and Public Health. 2020; 17(3326): 1-17.

[3] Edmonds-Wilson SL, Nurinova NI, Zapka CA, Fierer N, Wilson M. Review of human hand microbiome research. Journal of Dermatological Science. 2015; 80: 3-12.

[4] Jasim EI, Shawket DS, Mohsin YMB, Hasan AM, Mohammed BB. Estimate Bacterial Contamination of Iraqi Paper Currency and Effectiveness of Streptococcus CFS and Some Hand Wash to Limit its Spread. Indian Journal of Natural Sciences. 2018; 8(49) : 14298- 14307.

[5] Jones IA, Joshi LT. Biocide Use in the Antimicrobial Era: A Review. Molecules j. 2021; 26(2276) : 1-11.

[6] Boakye YD, Osafo N, Danquah CA, Adu F, Agyar C. Antimicrobial Agents: Antibacterial Agents, Anti-biofilm Agents, Antibacterial Natural Compounds, and Antibacterial Chemicals . Intechopen. 2019; 1-25.

[7] Hayek SA, Gyawali R, Ibrahim SA. Antimicrobial Natural Products. Microbial pathogens and strategies for combating them : science, technology and education.(A Méndez-Vilas).Formatex Research Center. 2013; 910921.

[8] Gobalakrishnan R, Bhuvaneswari R, Rajkumar M. Natural antimicrobial and bioactive compounds from Ludwigia parviflora Roxb. Journal of Analytical \& Pharmaceutical Research. 2020; 9(1): 37-42.

[9] Josh RK. Role of Natural Products against Microorganisms .American Journal of Clinical Microbiology and Antimicrobials. 2018; 1(1): 1-5.

[10] Mohammed BB, Najim SY, Shatti ZO , Jasim EI, Dari WA. Comparative study of antibacterial activity between the citrus limon(lemon) \& citrus aurantium (bitter orange) extracts on pseudomonas aeruginosa isolates from burns infections. Mintage Journal of Pharmaceutical \& Medical Sciences. 2018; 7(1): 20-23.

[11] AL-Oqaili RMS, Shaymaa Khudhr Al-Alak SA, Mohammed BB. Antibacterial Activity of Citrus Juices against Methicillin Resistant Staphylococcus aureus Journal of Biology, Agriculture and Healthcare. 2014; 4(7): 7-10.

[12] Gupta S, Gupta C, Prakash D, Garg AP. Comparative Study of Antimicrobial Effects of Lemon Oil Peel Extract against Food-Spoilage Microbes. J Nutrition Health Food Sci. 2017; 5(6): 1-5.

[13] Mohammed BB, Dari WA, Mohsin YMB. Effects of bioethanol produced by saccharomyces cerevisiae from some legumes residues on some pathogenic bacteria. Biochem. Cell. Arch. 2019; 19(1): 2571-2577.

[14] Palupi B, Fachri BA, Rahmawati I, Susanti A, Setiawan FA, Adinurani PG, Mel M. Bioethanol used as topical antiseptics: Pretreatment optimization of bioethanol production from tobacco industrial waste. Annals of Tropical Medicine \& Public Health. 2020; 23(8): 1-7.

[15] Saqib A. Antimicrobial Activity of Apple Cider Vinegar .Mapana Journal of Sciences. 2017; 16(2): 11-15.

[16] Baldas B, Altuner EM. The Antimicrobial Activity Of Apple Cider Vinegar And Grape Vinegar, Which Are Used As A Traditional Surface Disinfectant For Fruits And Vegetables . Communications Faculty of Sciences University of Ankara Series C: Biology. 2018; 27(1): 1-10.

[17] Cabezas-Pizarro J, Redondo-Solano M, Umana-Gamboa C, Arias-Echandi ML. Antimicrobial activity of different sodium and potassium salts of carboxylic acid against some common foodborne pathogens and spoilageassociated bacteria. Revista Argentina de Microbiología. 2018; 50(1): 56-61.

[18] Jasim EI, mohammed BB, Shawket DS. Lactobacillus casei isolated from human milk and three natural agents act as antibacterial against gram negative pathogenic Bacteria isolated from infected eye. International Journal of Current Microbiology and Applied Sciences. 2017; 6(4): 2568-2580.

[19] Goswami P, Kalita C, Bhuyan AC. Antibacterial Activity of Black Tea Extract against S. mutans, S. aureus,L. acidophilus, Klebsiella and E. coli. J Evolution Med. Dent. Sci. 2020; 9 (1): 18-22.

[20] Christaki E, Bonos E, Giannenas I, Florou-Paneri P. Aromatic Plants as a Source of Bioactive Compounds. Agriculture. 2012; 2: 228-243.

[21] Butnariu M, Sarac I. Essential Oils from Plants. Journal of Biotechnology and Biomedical Science. 2018;1(4): 3543.

[22] Mohammed BB. Study of the effect of selected commercial detergents (Soap, Wet wipes ) and probiotic Lactobacillus against bacteria isolated from paper currencies in Baghdad, Iraq. International Journal of Advanced Research. 2015; 3(3): 522-532. 
[23] mohammed BB, Shatti ZO, Dari WA, Mohsin YMB. Four screening methods to determine pediococcus acidilactici efficacy against two biofilm producing pathogenic bacteria. Indian Journal of Public Health Rresearch and Development. 2019; 10(10): 3810-3814.

[24] Baqer YM, Mohammed BB, Obaid KA, Ali Hlail ZA. CFS Of Lactobacillus: A Natural Agent Against Bacterialcontamination Of Cosmetics Tools. I.J.A.B.R . 2014; 4(3): 258-264.

[25] Paul RK, Dutta D, Chakraborty C, Nayak A, Dutta PK, Nag M . Antimicrobial agents from natural sources: An overview. Advance Pharmaceutical Journal. 2019; 4(2): 41-51.

[26] Muhsin YMB, Mohammed BB, Jasim EI, Shatti ZO. Synergistic Effect To Two Type Of Lactic Acid Bacteria And Their Synbiotic Effect With Prebiotic Raisin Against Some Pathogenic Bacteria . Journal of the College of Basic Education. 2017; 23(99): 141-152. 